\title{
Reforma do Ensino Médio e BNCC - Divisões, Disputas e Interdições de Sentidos
}

\author{
Claudia Pfeiffer ${ }^{2}$ \\ Marisa Grigoletto ${ }^{3}$
}

Resumo: Neste artigo analisamos a textualidade da reforma do ensino médio, instituída por lei federal em 2017, ancorando nosso gesto na textualidade da lei e suas relações intertextuais e interdiscursivas, observando, sobretudo, a proposta vigente da Base Nacional Comum Curricular (BNCC)no que se refere ao ensino de línguas. Procuramos trabalhar as equivocidades e contradições de uma política de estado educacional brasileira que estabelece lugares e sentidos para o ensino, o ensino de línguas, para os professores, a escola e os alunos, dentro de uma formação ideológica neoliberal na evidência da necessidade da formação significada enquanto capacitação para o trabalho.

Palavras-chave: Reforma do Ensino Médio. Base Nacional Comum Curricular. Ensino de línguas. PolíticasPúblicas.

\begin{abstract}
In this article the authors analyse the textuality of the Brazilian senior high school reform enacted by Federal law in 2017. This analysis focuses on the textuality of the law and its intertextual and interdiscursive relations, mainly observing the current proposal contained in the Base Nacional Comum Curricular (BNCC) - a national common curricular basis for secondary school instruction - as regards the teaching of languages. The authors attempt to explore the equivocities and contradictions of a Brazilian State educational policy that determines positions and meanings for teaching, the teaching of languages in particular, for teachers, school and students within the scope of a neoliberal ideological formation that functions on the evidence of the necessity of an education understood as capacity development for the labour market.

Keywords: Senior high school reform. National Common Curricular Basis.Language teaching.Public policies.

Riassunto: In questo articolo analizziamo la testualità della riforma della scuola media brasiliana, istituita con legge federale nel 2017, basandoci sulla testualità della legge e i suoi

\footnotetext{
${ }^{1}$ Texto apresentado no Simpósio O político-ideológico no ensino de língua(s), sob a coordenação das autoras, no VIII SEAD - Seminário de Estudos em Análise do Discurso, realizado na Universidade Federal de Pernambuco (UFPE), no período de 12 a 15 de setembro de 2017.

${ }^{2}$ Pesquisadora $(\mathrm{PqB})$ do Laboratório de Estudos Urbanos da UNICAMP e Professora Permanente do Programa de Pós-Graduação em Linguística do Instituto de Estudos da Linguagem da UNICAMP.

3 Livre-docente pela USP e professora aposentada, atuando, desde 2014, como Professor Colaborador Sênior, na mesma universidade.
} 
rapporti intertestuali e interdiscorsivi, osservando soprattutto la proposta attuale della Base Nacional Comum Curricular (BNCC) - base nazionale comune per il curriculum dell'istruzione secondaria - rispetto all'insegnamento delle lingue. Ci siamo proposte di riflettere sulle equivocità e sulle contraddizioni di una politica scolastica statale brasiliana che determina ruoli e percorsi per l'insegnamento, per l'insegnamento delle lingue, per i professori, per la scuola e per gli studenti, nell'ambito di una formazione ideologica neoliberale che mette in evidenza la necessità di una formazione efficace intesa come sviluppo delle capacità di lavoro.

Parole-chiave: Riforma della scuola media. Base nazionale comune per il curriculum scolastico. Insegnamentodelle lingue. Politichepubbliche.

\section{Introdução}

Nosso trabalho incide sobre a reforma do ensino médio aprovada em 16 de fevereiro de 2017. Ancoramos nosso gesto na textualidade da lei e suas relações intertextuais e interdiscursivas, observando direções de sentido nela configuradas que marcam divisões, disputas e interdições.

Procuraremos trabalhar as equivocidades e contradições de uma política educacional de Estado que estabelece lugares e sentidos para o ensino dentro de uma formação ideológica neoliberal na evidência da necessidade da formação significada enquanto capacitação para o trabalho.

Nossa entrada analítica se dará pela forma material itinerários formativos, que já foi objeto de compreensão em trabalho anterior (PFEIFFER, 2017), para dela seguir por suas redes de significação.

\section{Nossa análise}

Tomando a textualidade da lei enquanto "um gesto de formulação que consuma o imaginário no sujeito" (ORLANDI, 1996, p. 40), trazemos o artigo 36 da lei, no qual está presente a forma material itinerários formativos, que será trabalhada, como nos propõe Orlandi (2001, p. 19), enquanto "forma encarnada na história para produzir sentidos": 
Art. 36. O currículo do ensino médio será composto pela Base Nacional Comum Curricular e por itinerários formativos, que deverão ser organizados por meio da oferta de diferentes arranjos curriculares, conforme a relevância para o contexto local e a possibilidade dos sistemas de ensino, a saber:

I - linguagens e suas tecnologias;

II - matemática e suas tecnologias;

III - ciências da natureza e suas tecnologias;

IV - ciências humanas e sociais aplicadas;

$\mathrm{V}$ - formação técnica e profissional (BRASIL. Lei 13.415/2017, p.3). ${ }^{4}$

Queremos chamar a atenção para uma rede discursiva que se estabelece a partir de Itinerários Formativos que é posto em relação à Base Nacional Comum Curricular, uma vez que ambos comporão o currículo do Ensino Médio. Composição esta que é articulada a diferentes arranjos curriculares, que ressoa, por sua vez, em um movimento próprio de nosso tempo: flexibilização. Estas articulações - os itinerários, a Base e os arranjos - estão condicionadas: elas estarão presentes na medida em que sejam relevantes para o contexto local e na medida da possibilidade estrutural de cada escola.

Temos aí uma espessura densa de sentidos que materializa um contínuo batimento entre memória e atualização (PÊCHEUX, 1999). Para dizer o mínimo e nos situando frente à nossa análise, temos em jogo: o currículo, oriundo, de modo naturalizado e evidente, de uma base curricular comum; as escolhas, significadas como reflexos dos desejos, sonhos e vontades individuais, sem mediação de ordem alguma; a relevância, na qual se apagam as relações de força e de sentido aí presentes: quem decide, de que modo, com quais critérios, com qual periodicidade?; e as condições estruturais das escolas, que obviamente restringirão consideravelmente as possibilidades de oferta dos itinerários, silenciando a contradição entre, imaginariamente, tudo oferecer a todos e, sob as reais condições materiais de existência, a interdição e a divisão se assentarem ${ }^{5}$. Para esta nossa reflexão, nos deteremos nos dois primeiros pontos em jogo, passando de maneira mais breve por este último.

\footnotetext{
${ }^{4}$ Todos os grifos (negritos, itálicos e sublinhados) são nossos em todos os recortes analisados no presente capítulo. Caso o grifo seja do original, informaremos.

5 Ainda poderíamos perguntar: como lidar com as impossibilidades dos sistemas de ensino? $\mathrm{Ou}$ melhor, como resistir àquilo que se apresenta enquanto uma impossibilidade?
} 


\section{A Reforma na mídia}

Primeiramente, vamos estender nosso gesto de análise ao discurso da mídia, materializado em textos de divulgação e explicação da reforma do ensino médio para o público leigo, nos quais encontramos reverberações do discurso oficial textualizado na lei e em justificativas do MEC sobre a reforma. Observamos que, na articulação entre a questão das escolhas e as condições estruturais da escola, a mídia reproduz a contradição estabelecida pelo discurso oficial, contribuindo, assim, para a naturalização do jogo contraditório.

Na discursividade da mídia, a espessura densa de sentidos posta em jogo na textualidade da lei parece se esgarçar sob o efeito de evidência dos significantes escolha, oferta e interesse:

O texto determina que $60 \%$ da carga horária seja ocupada obrigatoriamente por conteúdos comuns da BNCC, enquanto os demais $40 \%$ serão optativos, conforme a oferta da escola e interesse do aluno, mas também seguindo o que for determinado pela Base Nacional. No conteúdo optativo, o aluno poderá, caso haja a oferta, se concentrar em uma das cinco áreasmencionadas acima(G1: Entenda a reforma do ensino médio).

Nesta primeira formulação, a oferta da escola e o interesse do aluno são colocados em relação semântica de adição, ligados pela conjunção $e$, produzindo o efeito de que ambas as condições podem se realizar plenamente no mesmo espaço e sob uma mesma estrutura escolar. Tal efeito de soma se rompe, porém, com a introdução da ressalva de que caso haja a oferta [pela escola], o aluno poderá se concentrar em uma das 5 áreas. A introdução dessa ressalva no fio discursivo ressignifica os significantes oferta e interesse, provocando o deslizamento do sentido de adição para outra condição, mais restritiva: a oferta da escola pode restringir, ou mesmo ignorar, o atendimento ao interesse do aluno, este tomado em sua condição de sujeito individua(liza)do, num processo que será analisado adiante.

Na segunda formulação, abaixo, o modo como são postas em relação oferta e escolha também produz um deslizamento de sentidos que parte da oportunidade de escolha para chegar à possível restrição da oferta: 
O que são os itinerários formativos?

A flexibilidade do currículo proposta pela reforma do Ensino Médio também implica que os alunos terão a oportunidade de escolher em qual área do conhecimento desejam se aprofundar. No texto aprovado do Senado, ficaram definidos cinco itinerários formativos possíveis: Linguagens, Matemática, Ciências da Natureza, Ciências Humanas e Formação Técnica e Profissional. Porém, as escolas não são obrigadas a oferecer todos os percursos, nem disponibilizar a escolha de aprofundamento $\operatorname{logo}$ no $1^{\mathbf{0}}$ ano. Elas poderão escolher o que vão ofertar de acordo com a relevância para o contexto local e as possibilidades das redes de ensino à qual pertencem. Caso uma unidade educacional ofereça mais de um percurso, o estudante poderá optar por mais de um. (N Notícias (Nova Escola): 13 respostas sobre o Novo Ensino Médio)

$\mathrm{Na}$ materialidade textual, a flexibilidade do currículo é explicada como oportunidade de escolha que os alunos terão para, na sequência, ser introduzida a ressalva (Porém) de que a oferta das escolas não precisa ser plena (todos os percursos), uma vez que, explica-se, as escolas poderão escolher o que ofertar. No final da formulação, a escolha do estudante é referida uma vez mais, condicionada, contudo, à oferta decidida pela escola, em que a condicionante "Caso uma unidade educacional ofereça mais de um percurso" comparece sob a forma de um pré-construído.

Podemos observar aí o efeito metafórico (pontos de deriva) em funcionamento no discurso, como fruto de um "gesto de interpretação fazendo-se na relação da estrutura com o acontecimento, jogo da contradição" (ORLANDI, 2005, p. 86). O sentido aparentemente estabilizado na "evidência" de formulações sobre a oportunidade de escolha do estudante desliza e deixa ver a equivocidade da fórmula $X$ poderá escolher.

Nesse movimento dos sentidos, a tão decantada flexibilidade do currículo (palavra de ordem na Reforma do Ensino Médio, na qual ecoam fortemente sentidos de uma política de cunho neoliberal) reveste-se de opacidade.

Voltaremos a essa reflexão mais adiante, uma vez que queremos colocá-la ao lado de nossa análise sobre a BNCC.

\section{A Base Nacional em análise}

O primeiro ponto que queremos observar é o de que, na recente aprovação da BNCC, em abril de 2017, o Ensino Médio não está incluído. O MEC justifica isso afirmando que a Reforma do Ensino Médio exige outras modificações na BNCC. Ao 
mesmo tempo o "Novo" Ensino Médio só pode ser iniciado, após a aprovação da BNCC, que é assim definida na página do Ministério da Educação ${ }^{6}$ :

\begin{abstract}
A Base Nacional Comum Curricular (BNCC) é um conjunto de orientações que deverá nortear os currículos das escolas, redes públicas e privadas de ensino, de todo o Brasil. A Base trará os conhecimentos essenciais, as competências e as aprendizagens pretendidas para crianças e jovens em cada etapa da educação básica em todo país. A BNCC pretende promover a elevação da qualidade do ensino no país por meio de uma referência comum obrigatória para todas as escolas de educação básica, respeitando a autonomia assegurada pela Constituição aos entes federados e às escolas.
\end{abstract}

Trazemos ainda do MEC (idem) mais dois recortes:

O currículo do novo ensino médio será norteado pela Base Nacional Comum Curricular (BNCC), obrigatória e comum a todas as escolas (da educação infantil ao ensino médio). A BNCC definirá as competências e conhecimentos essenciais que deverão ser oferecidos a todos os estudantes na parte comum (1.80o horas), abrangendo as 4 áreas do conhecimento e todos os componentes curriculares do ensino médio definidos na LDB e nas diretrizes curriculares nacionais de educação básica.(...) As disciplinas obrigatórias nos 3 anos de ensino médio serão língua portuguesa e matemática. $\mathrm{O}$ restante do tempo será dedicado ao aprofundamento acadêmico nas áreas eletivas ou a cursos técnicos, a seguir: I - linguagens e suas tecnologias; II - matemática e suas tecnologias; III - ciências da natureza e suas tecnologias; IV - ciências humanas e sociais aplicadas; V - formação técnica e profissional. Cada estado e o Distrito Federal organizarão os seus currículos considerando a BNCC e as demandas dos jovens, que terão maiores chances de fazer suas escolhas e construir seu projeto de vida.

Anteriormente, a LDB não trazia a língua inglesa como estudo obrigatório. A reforma torna o inglês obrigatório desde o 60 ano do ensino fundamental e no ensino médio. Os sistemas de ensino poderão ofertar outras línguas estrangeiras se assim desejarem, preferencialmente o espanhol. A língua inglesa é a mais disseminada e a mais ensinada no mundo inteiro.

E do Movimento Pela Base Comum Nacional, trazemos:

\footnotetext{
${ }^{6}$ http://portal.mec.gov.br/component/content/article?id=40361
} 
A base nacional comum "vai promover a equidade, uma vez que garante a todos os brasileiros o acesso a um conjunto de conhecimentos considerados essenciais para concretizar seus projetos de vida"7.

Poderíamos traçar percursos por diferentes pontos de ancoragem que estabelecem entre si relações equívocas e contraditórias como a presença regular de algo que é comum e, portanto, obrigatório - apesar de ser significado como uma orientação - e de algo que é eletivo. Fora disso, à parte de tudo, flutuando em sua evidência histórica, encontramos o ensino técnico. Na relação entre estes três lugares de injunção, duas disciplinas são erigidas como intocáveis e fundamentais: a língua portuguesa e a matemática (e sabemos muito bem que aí estão porque são significadas como a materialização do fracasso escolar nos números estatísticos e nas avaliações nacionais e internacionais, são o carro chefe da tragédia anunciada). Este comum e obrigatório se dá em relação a universais, a totalidades como "todo o Brasil", "todas as escolas" (públicas e privadas). Esse movimento tem um duplo objetivo: a elevação da qualidade do ensino e a garantia da realização dos projetos de vida individuais. Além disso, justificando-se pela revogação da obrigatoriedade do ensino do espanhol, esta textualidade afirma a língua inglesa como prioritária, sustentando-se na Formação Ideológica da Mundialização, mas, claro, abrindo espaço - sempre! - a outras línguas a serem ensinadas no mesmo lugar dos itinerários: desejando, tudo é possível.

Vamos aqui nos ater a dois pontos: a evidência da necessidade do comum, do nacional e o lugar desse comum e obrigatório como possibilidade de justiça social, uma vez que o ensino de língua estrangeira será trabalhado adiante.

O comum e o obrigatório na Base

A Base Curricular está inserida em uma rede de significação na qual a LDB de 1996 e os Parâmetros Curriculares (assim como vários outros documentos) significam fortemente. Propomos seguir aqui com análises realizadas por Silva (2017), de modo a melhor compreender as filiações de sentido (a memória discursiva) sob as quais se sustenta a Base Curricular.

\footnotetext{
${ }^{7}$ Site Movimento pela Base Comum Nacional. Disponível em: <http://basenacionalcomum.org.br/porque-criar-uma-base-comum-brasil/s.
} 
A autora nos mostra que os Parâmetros Curriculares de 1996 constroem a “'cidadania' como efeito de sentido, efeito ideológico”. Para Silva, na Apresentação do Volume Introdutório dos PCNs,

A cidadania já é o elemento nuclear para uma ampla análise da conjuntura mundial e brasileira nos termos de um discurso sociologizante, em que se explicitam tensões a serem enfrentadas pelo Estado. (SILVA, 2017, p. 319)

É este efeito de sentido, efeito ideológico que permite, segundo Silva, "a movimentação de sentidos no processo de individua(liza)ção do sujeito no espaço político e simbólico da urbanização - pobre, excluído - em que busca valer seus direitos" (SILVA, 2017, 319).

É também no bojo desse efeito que, para a autora, "o problema da desigualdade de classe social" é deslocado "para a desigualdade educacional, sendo a educação tomada como capaz de superar a desigualdade primeira" (SILVA, 2017, p. 321).

Guardando essa importante compreensão, e para nos situarmos frente às condições de produção da Base Nacional Comum Curricular discutida desde 2015, retomamos ainda Silva (2017, p. 323) que nos mostra que esse efeito de cidadania e inclusão com vistas à superação da desigualdade social dos PCNs desliza, 20 anos depois, para o efeito de sentido de um sujeito com "direitos à aprendizagem e ao desenvolvimento" em relação a "princípios éticos, políticos e estéticos”, redefinindo a cidadania no campo das políticas públicas de educação em que a inclusão, pela via jurídica, "em conformidade com os princípios éticos, políticos e estéticos" (BNCC, 2016, p. 35), "tende a neutralizar as divisões, os conflitos, possibilitando que a sociedade, o sujeito, a língua se apresentem e se representem como visíveis" (SILVA, 2017, p. 323).

Apagamento e transparência que funcionam tão consistentemente na evidência da necessidade de uma base comum e, ao mesmo tempo, na necessidade da flexibilização curricular em nome do indivíduo, sustentados em um mesmo solo discursivo: o livre-arbítrio, a construção da equidade, o respeito às diferenças, à justiça social conquistada pela capacidade, pelo talento, pela vocação de cada indivíduo.

E como funciona a construção de um currículo que dê conta dessa necessidade e evidência histórica? Primeiramente, é preciso lembrar, com Macedo (2016, p. 55), que 
“a teoria curricular é política, ou seja, é parte da luta por significar sentidos para, entre outros, o currículo escolar". Segundo esta autora, teríamos, no momento, uma disputa entre fixar o conhecimento em si ou o conhecimento para fazer algo como aquilo que deveria ser estruturante da Base Curricular.

As análises de Macedo nos permitem compreender que essas seriam duas posições aparentemente antagônicas que se sustentam em uma mesma justificativa: a justiça social, a construção de uma igualdade. E ambas articuladas a um lugar comum de avaliação - as diferentes provas nacionais e internacionais - que certificam e atestam se há ou não, seja conhecimento (anteriormente validado como o melhor e o correto), sejam capacidades de fazer. Processo de certificação e validação que sustenta a necessidade contínua de estratificação do mercado. Como diz Macedo (2016, p. 6263), "o mercado não pode prescindir de estratificação, mesmo que esconda essa necessidade".

Sustentando não apenas que as duas posições sobre as bases nacionais curriculares incidem em um mesmo equívoco, como também justificando sua posição contrária à própria proposição de um currículo comum, Macedo afirma que essa unidade, seja hoje calcada no pragmatismo neoliberal ou em um núcleo primordial e verdadeiro do conhecimento, expulsa

da educação toda diferença e toda singularidade que não são, por natureza, antecipáveis e sem as quais educação, justiça e democracia não fazem sentido. Porque educação, justiça e democracia requerem alteridade para serem vividas como tal (MACEDO, 2016, p. 63).

Antecipando-se àquilo que já é consensual no lugar da gestão, enquanto a evidência da necessidade da unidade, da checagem, do controle, Macedo afirma que "em termos de políticas públicas, a opção pelo imprevisível pode parecer idílica, mas não há alternativa para políticas que pretendem educar" (MACEDO, 2016, p.63).

E continua a autora

É uma aposta que constitui, sem dúvida, um desafio mais difícil do que produzir uma lista (de conteúdos ou de capacidades de fazer) que sirva de base comum nacional. Ela envolve formar bem os professores, e, principalmente, dar-lhes condições de trabalho e salário compatíveis, investir 
nas escolas e no trabalho lá realizado, enfim, valorizar a educação, e não o controle que a destrói como empreitada intersubjetiva(MACEDO, 2016, p. 63).

Mas é o controle que se materializa na Reforma do Ensino Médio, na relação necessária com a BNCC, na evidência da igualdade e da justiça social, na evidência do todos podem e escolhem o que querem.

\section{Língua estrangeira na BNCC}

As disposições sobre o ensino de línguas estrangeiras na BNCC e na Lei no 13.415 , que instituiu a reforma do ensino médio, também nos levam a refletir sobre as contradições da política educacional no que se refere às "escolhas" da comunidade escolar, que, de fato, são cada vez mais reduzidas.

Há uma mudança radical da segunda para a terceira versão da Base Nacional Comum Curricular no componente relativo ao ensino de língua(s) estrangeira(s) moderna(s). A segunda versão da BNCC, publicada em 2016 (versão completa que incluía as diretrizes para todos os anos e ciclos da educação básica), seguia a determinação da LDB de 1996, que estipulava, a partir da quinta série do ensino fundamental, o ensino de pelo menos uma língua estrangeira moderna, cuja escolha ficará a cargo da comunidade escolar. No ensino médio, essa obrigatoriedade se mantinha (uma língua estrangeira moderna, como disciplina obrigatória, escolhida pela comunidade escolar), acrescida de uma segunda língua estrangeira, cuja oferta deveria ser obrigatória para a instituição escolar, mas de caráter optativo para o aluno. Já a terceira versão da BNCC, publicada em 2017, mas sem a inclusão do segmento referente ao ensino médio, ainda em elaboração e prometido para final de 2018, estabelece que a língua estrangeira obrigatoriamente ofertada a partir do sexto ano do ensino fundamental será a língua inglesa. A Lei no 13.415 estendeu essa obrigatoriedade também para o ensino médio, provocando uma alteração na LDB de 1996, que, em sua versão atualizada até março de 2017, dispõe:

Art. 35-A.

$\S 4^{\mathrm{o}}$ Os currículos do ensino médio incluirão, obrigatoriamente, o estudo da língua inglesa e poderão ofertar outras línguas estrangeiras, em caráter optativo, preferencialmente o espanhol, de acordo com a disponibilidade de oferta, locais e horários definidos pelos sistemas de ensino. 
Extingue-se a obrigatoriedade de oferta de uma segunda língua estrangeira no ensino médio, que passa a ser de oferta opcional pelas escolas.

Assim, no que tange ao ensino de línguas estrangeiras, tanto a Lei no 13.415 quanto a terceira versão da BNCC instauram, como parte de uma política de estado educacional brasileira, o gesto político e jurídico de imposição legal da língua inglesa como a língua estrangeira obrigatória na escola básica brasileira, desde o sexto ano do ensino fundamental até o último ano do ensino médio. $\mathrm{O}$ que anteriormente figurava como possibilidade de pluralidade de línguas estrangeiras na textualidade dos documentos legais ${ }^{8}$, reduziu-se à oferta de uma só língua e uma língua determinada, o inglês.

Trata-se de um gesto político e ideológico que, no entanto, fica encoberto pelo efeito de evidência de que não há outra escolha possível de língua estrangeira a ser ensinada na escola básica brasileira. Afinal, a língua inglesa é a mais disseminada e a mais ensinada no mundo inteiro, justifica o texto do MEC citado acima, de modo que:

\begin{abstract}
Aprender a língua inglesa propicia a criação de novas formas de engajamento e participação dos alunos em um mundo social cada vez mais globalizado e plural, em que as fronteiras entre países e interesses pessoais, locais, regionais, nacionais e transnacionais estão cada vez mais difusas e contraditórias (BNCC,

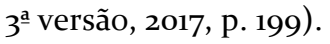

Produz-se, desse modo, um efeito de evidência sobre a necessidade do aprendizado da língua inglesa - em razão de vivermos em um mundo social cada vez mais globalizado e plural e nos depararmos com fronteiras entre países e interesses pessoais, locais, regionais, nacionais e transnacionais [...] cada vez mais difusas e contraditórias - porque se estabelece uma relação de causalidade entre:

\footnotetext{
${ }^{8}$ Esta é, dentre outras, uma formulação que significa a partir do sentido de pluralidade: "Entende-se, ainda, como desafio, a articulação entre línguas estrangeiras, tendo-se em vista a pluralidade das ofertas possíveis, não se restringindo apenas ao inglês e ao espanhol. Para tanto, é importante que cada comunidade escolar possa [...] escolher as línguas estrangeiras a serem ministradas [...]" (BNCC, $2^{\mathrm{a}}$ versão, p. 124).
} 
mundo globalizado e plural + fronteiras difusas e contraditórias (causa)

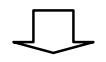

determinação da língua inglesa como língua estrangeira obrigatória na escola brasileira (consequência)

Relação essa que exclui a possibilidade de que outra língua estrangeira propicie o engajamento dos alunos em um mundo plural.

Reforça-se, ainda, a associação entre o aprendizado do inglês e a exposição à pluralidade do mundo com a justificativa de que se faça "a opção pelo ensino da língua inglesa como língua franca":

Trata-se, portanto, de definir a opção pelo ensino da língua inglesa como língua franca, uma língua de comunicação internacional utilizada por falantes espalhados no mundo inteiro, com diferentes repertórios linguísticos e culturais (BNCC, $3^{\mathrm{a}}$ versão, 2017, p. 199).

A "participação dos alunos em um mundo social cada vez mais globalizado e plural" estaria garantida pelo aprendizado de uma língua falada no mundo inteiro, por pessoas com "diferentes repertórios linguísticos e culturais". A ausência de menção a outras línguas estrangeiras no texto da BNCC e o efeito de sentido produzido pela vinculação estreita entre "pluralidade" e língua inglesa constroem o efeito de evidência de que o inglês é suficiente e bastante para atingir os objetivos de uma educação linguística em língua estrangeira na escola básica brasileira. Impõe-se o ensino de uma mesma língua para todos no país, ao mesmo tempo em que se afirma garantir as demandas dos alunos para que possam construir seus projetos de vida individuais.

Com isso, também o significante interculturalidade que, na segunda versão da BNCC, era apresentado como justificativa desejável para o aprendizado de línguas estrangeiras, reduz-se, agora, ao aprendizado do inglês.

Esse entendimento [do inglês como língua franca, desvinculado do pertencimento a um determinado território] favorece uma educação linguística voltada para a interculturalidade, isto é, para o reconhecimento das (e o respeito às) diferenças, e para a compreensão de como elas são produzidas(BNCC, 3를 versão, 2017, p. 199). 
Concluímos que, na textualidade desses documentos, significantes que apontam para a pluralidade, diversidade e abertura às diferenças culturais no contato com línguas estrangeiras têm seus sentidos restringidos à relação com a língua inglesa, reforçando, assim, as equivocidades e contradições dessa política educacional de viés utilitarista dentro de uma formação ideológica neoliberal que se coaduna com aquilo que faz funcionar a Reforma do Ensino Médio, o que nos permite retornar para a nossa porta de entrada na análise, a forma material itinerários formativos.

\section{O Itinerário em análise}

Dando continuidade à análise, retomaremos a compreensão de Pfeiffer (2017) que se debruçou na intertextualidade entre a lei e a justificativa do Ministério da Educação junto à Presidência da República para fazer seguir o projeto de Lei ao Congresso Nacional que incidiu sobre a relação entre "itinerários formativos", "escolha", "opção" e "projeto de vida", permitindo ver, nessa rede de sentidos, a construção do efeito de evidência de liberdade e de individualidade. O projeto de vida é do aluno. E é sua também a escolha ou opção do itinerário que melhor corresponde a este projeto.

Queremos agora colocar essa compreensão em relação com o que está disposto na página do Ministério da Educação ${ }^{9}$, para mostrar a força dessa regularidade:

\footnotetext{
A reforma do ensino médio é uma mudança na estrutura do sistema atual do ensino médio. Trata-se de um instrumento fundamental para a melhoria da educação no país. Ao propor a flexibilização da grade curricular, o novo modelo permitirá que o estudante escolha a área de conhecimento para aprofundar seus estudos. A nova estrutura terá uma parte que será comum e obrigatória a todas as escolas (Base Nacional Comum Curricular) e outra parte flexível. Com isso, o ensino médio aproximará ainda mais a escola da realidade dos estudantes à luz das novas demandas profissionais do mercado de trabalho. E, sobretudo, permitirá que cada um siga o caminho de suas vocações $e$ sonhos, seja para seguir os estudos no nível superior, seja para entrar no mundodo trabalho.

Cada estado e o Distrito Federal organizarão os seus currículos considerando a BNCC e as demandas dos jovens, que terão maiores chances de fazer suas escolhas e construir seu projeto de vida.
}

A edição da Medida Provisória (MP) seguiu rigorosamente as exigências previstas na Constituição Federal. Em primeiro lugar, em decorrência da

\footnotetext{
${ }^{9}$ http://portal.mec.gov.br/component/content/article?id=40361
} 
urgência do problema desse nível de ensino no país, dados do IDEB recémdivulgados mostram uma realidade trágica no ensino médio e retratam a urgência da reforma. Em segundo lugar, em consequência da relevância do tema que se apresenta na medida em que o fracasso do ensino médio brasileiro é um dado da realidade, como demonstram os resultados das avaliações nacionais e internacionais. As propostas da MP são fruto do amplo debate acumulado no país nas últimas décadas, o que permitiu ao governo acelerar a reforma.

Diante do argumento do fracasso ${ }^{10}$, traz-se junto a solução do dia para tudo resolver: a oferta de um ensino à la carte, cada freguês escolhe o seu. E o cardápio também será definido em função do gosto, do desejo do freguês, uma vez que teremos, finalmente, um ensino que responderá às demandas dos jovens, permitindo que a escola esteja próxima à realidade de cada um dos estudantes.

Se por um lado temos a materialização de uma discursividade construída historicamente sob a égide do individualismo, do trabalho e da superação, ou, dito de outro modo, sob a evidência da educação como meio e modo de liberdade, de atendimento das vontades e desejos individuais, da superação da desigualdade pela eliminação dos obstáculos; por outro lado temos, e sustentada por essa discursividade instaurada pela Revolução Burguesa, a legitimação da divisão e da interdição" .

Para que esse duplo movimento fique mais visível, vamos retornar ao ir-e-vir entre a lei e o documento que a justificou. Conforme analisado anteriormente (PFEIFFER, 2017), na textualidade das justificativas encontramos a regularidade de afirmar a "existência de um descompasso" entre os objetivos propostos para o Ensino Médio na LDB de 1996 e a assim chamada realidade. Segundo este argumento, o ensino médio deveria "consolidar e aprofundar os conhecimentos adquiridos no ensino fundamental, bem como formar indivíduos autônomos, capazes de intervir e

\footnotetext{
${ }^{10} \mathrm{O}$ fracasso da vez é o do ensino médio, mas isso pouco importa quando se fala da educação no Brasil, pois todos sabem, sempre souberam, e os números sempre mostram inequivocamente isso, que se trata de um fracasso apresentado como irrefutável pela construção histórico-ideológica das estatísticas sustentadas pelas inúmeras avaliações que estabilizam no imaginário social brasileiro a educação como um problema eterno. No entanto, não se trata de qualquer educação. Sem que seja necessário explicitá-la, a referência discursiva é a educação pública.

${ }^{11}$ É preciso salientar, nos intensos e extensos embates que marcaram a instituição da Revolução Burguesa, o fundamental papel que teve a instauração da conclamação pela liberdade como um ponto sem retorno sobre o qual se ancora a Revolução. É justamente a evidência da liberdade, na sua relação com a igualdade, que sustenta a possibilidade de se substituir o privilégio pela oportunidade: nada mais é dado a princípio, mas sim conquistado, o que permite centrar no indivíduo as possibilidades de bem aproveitar as oportunidades. O livre-arbítrio, sua evidência, garantida pela instituição de que não há ninguém a priori com mais vantagem do que outro, havendo apenas as virtudes naturais que precisam ser destacadas, destacáveis e bem aproveitadas, igualmente.
} 
transformar a realidade" (BRASIL, EM. 84/2016/MEC, p. 1). E o que justifica que isso não se realize seria o assim considerado extenso, fragmentado e superficial currículo ofertado: “atualmente o ensino médio possui um currículo extenso, superficial e fragmentado, que não dialoga com a juventude, com o setor produtivo, tampouco com as demandas do século XXI" (BRASIL, EM. 84/2016/MEC, p.1).Ou seja, o projeto de vida, com base no qual estes itinerários seriam escolhidos, segundo essa discursividade, pode se realizar de modo pragmático - dentro das demandas do século XXI e dialogando com o setor produtivo - garantindo, assim, veremos isso mais adiante, que o ensino ganhe sentido.

Se essa justificativa joga com a evidência dos referentes de "juventude", "setor produtivo" e "demandas do século XXI", isso se torna muito mais potente na relação com o argumento sustentado pelas estatísticas, que funciona, por sua vez, enquanto efeito de verdade, muito presente nas políticas públicas em geral, e que, no caso específico daquelas relativas à educação, promove a legitimação das divisões. Vejamos.

Uma pesquisa do CEBRAP e da Fundação Victor Civita ${ }^{12}$, afirma essa textualidade, "evidenciou que os jovens de baixa renda não veem sentido no que a escola ensina" (idem). De nosso ponto de vista, temos aí a materialização da divisão. Aquilo que não se afirmava até esse momento, mas era continuamente significado pela memória discursiva que se instala a cada tomada de palavra nessa discursividade, sustentada por um discurso fundador da instrução pública instaurada contraditoriamente na Revolução Burguesa ${ }^{13}$, é o fato discursivo de que o problema do Ensino Médio, ou da juventude, tem um referente - igualmente discursivo: os jovens de baixa renda.

O descompasso é com estes jovens. A forma material itinerários formativos materializa o mundo que não cessa de se dividir, como nos fala Pêcheux (1990), ao

\footnotetext{
${ }^{12}$ Não pudemos nos ater no trabalho anterior e aqui também não conseguiremos avançar igualmente na importância das instituições nos processos discursivos. De todo modo, voltamos a salientar a presença da Fundação Victor Civita e as sobreposições entre órgãos públicos e privados na configuração de instrumentos públicos que dão visibilidade para regiões de sentidos específicas, sustentando as formações imaginárias com as quais as políticas públicas e as formações sociais, incontornavelmente, se defrontam.

${ }^{13}$ Lembramos aqui - fato discursivo sobre o qual estamos trabalhando em pesquisa em andamento-, o artigo $6^{\circ}$. da Constituição de 1789: "A lei deve ser igual para todos, quer quando protege, quer quando pune. A seus olhos todos os cidadãos são iguais e têm acesso, em igualdade de condições, a todas as dignidades, cargos e empregos públicos, segundo sua capacidade, e sem outra distinção que a de suas virtudes e talentos."
} 
tratar da especificidade da divisão de classes no modo de produção capitalista a partir do corte com o modo de produção feudal, ao afirmar que o jogo entre dominação e resistência, após a Revolução Burguesa, se dá a partir de uma divisão no interior das lutas ideológicas constituída por uma barreira política invisível e não necessariamente pela separação dos sujeitos em dois "mundos". Para Pêcheux (2015), o processo ideológico de dissimulação da desigualdade real na unidade imaginária é uma questão que produz efeitos na linguagem. E é isso que viemos observando funcionar. "Itinerário formativo" é uma forma material que se dá no interior de formações sociais que, para Pêcheux (2015), em sua leitura marxista, se caracterizam pelo modo de produção que as domina e por um estado dado pelas relações sociais de classes que as compõe.

A proposta dos itinerários, portanto, entre outras filiações de sentido e outros efeitos de sentido, estabiliza, em um mundo semanticamente estável, que o que se ensina está desalinhado ao mundo do trabalho e, consequentemente, o sentido do ensino, para alguns, não todos, é sempre preciso lembrar, está no alinhamento ao mundo do trabalho. É aí que "naturalmente", por suposto, deve estar a escolha deste jovem específico - o pobre da escola pública. A escolha por um itinerário formativo condizente com seu projeto de vida: o mínimo e o necessário ${ }^{14}$ para atender com qualidade ao mundo do trabalho.

\section{Considerações finais}

Fechamos nosso trajeto, reafirmando que a Reforma do Ensino Médio, que só pode vir a ser implementada com a aprovação da Base Nacional Curricular, implica, por estas condições de produção que viemos analisando, na redução do aluno à evidência de um jovem - não qualquer um - que é responsável pela queda dos números positivos na educação, mas que também é, contraditoriamente, um jovem

\footnotetext{
${ }^{14}$ Outra ancoragem que não iremos trabalhar aqui em termos de memória discursiva da instrução pública burguesa, e que está sendo trabalhada em pesquisa em andamento, é o fato discursivo de encontrarmos nos cahiers de dóleances, que consistiram em exigências e reivindicações documentadas no processo da Revolução Burguesa e que deveriam ser levadas em conta pela Assembleia Nacional, a regularidade da demanda por uma "educação suficiente aos que habitam e que possam se estender atémesmo aos pobres".
} 
necessário. Dito de outro modo, este jovem precisa estar no sistema educacional e, para tanto, é necessário que se ofereça "um currículo atrativo e convergente com as demandas para um desenvolvimento sustentável” (Brasil, EM. 84/2016/MEC, p. 2). Isso porque este jovem é significado como responsável, ao entrar no sistema educacional, pela queda dos resultados educacionais que é, por sua vez, explicada pelo fato dele não ver sentido algum no que a escola ensina, porque o que se ensina está desalinhado ao mundo do trabalho e, consequentemente, o sentido do ensino, para alguns, não todos, está no alinhamento a este mundo: o do emprego.

É aí, também, a que é reduzido o lugar do professor: aquele que frente às impossibilidades dos sistemas de ensino, frente às relevâncias locais, frente ao setor

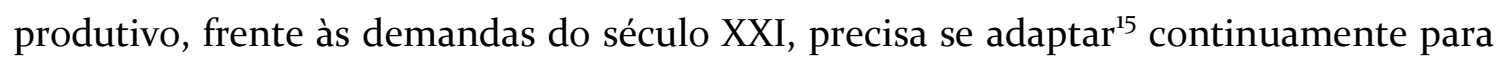
capacitar este aluno, este jovem pobre e não qualquer um, para atender com qualidade ao mundo do trabalho. Apagamento duplo, na divisão: aluno e professor interditados na relação com o conhecimento, com o imprevisível, com a autoria ${ }^{16}$, que os limita igualmente em suas possibilidades de conhecimento de outras línguas e culturas, porque tomados como sujeitos necessitados não de formação, mas, tão somente, de capacitação ${ }^{17}$.

\section{Referências}

MACEDO, E. Base nacional curricular comum: a falsa oposição entre conhecimento para fazer algo e conhecimento em si. Educação em Revista, Belo Horizonte, v.32, n.o2. Abril-Junho 2016. p. 45-67.

ORLANDI, E. A Análise de Discurso em suas diferentes tradições intelectuais: o Brasil. In: INDURSKY, F.; FERREIRA, M. C. L. (Orgs.).Michel Pêcheux e a análise do discurso: uma relação de nunca acabar. São Carlos: Claraluz, 2005· p. 75-88.

. Análise de Discurso. Princípios e Procedimentos. Campinas: Pontes, 2001.

\footnotetext{
${ }^{15}$ Quanto a isso, cf. Pfeiffer (2010).

${ }_{17}^{16}$ Quanto a isso, cf. Pfeiffer (1995).

17 Remetemo-nos a trabalhos mais recentes de EniOrlandi em que a autora discute a relação entre formação e capacitação (cf. Orlandi, 2014) e entre conhecimento e informação (cf. Orlandi, 2016).
} 
.Educação e sociedade: o discurso pedagógico entre o conhecimento e a informação. Revista ALED, n. 16(2), 2016. p. 68-8o.

. Formação ou capacitação: duas formas de ligação sociedade e conhecimento.

In: FERREIRA, E. L.; ORLANDI, E. P. (Orgs). Discursos sobre a inclusão. Niterói: Intertexto, 2014. p.148-16o.

. Interpretação; autoria, leitura e efeitos do trabalho simbólico. Petrópolis:

Vozes, 1996.

PÊCHEUX, M. Delimitações, inversões, deslocamentos. Tradução de José Horta Nunes. Cadernos de Estudos Linguísticos, n. 19, Campinas: IEL/UNICAMP, 1990. p. 7-24.

- Ousar pensar e ousar se revoltar: ideologia, marxismo, luta de classes. Décalages, v.1, n. 4, 2015. p. 1-22.

- Papel da memória. In: ACHARD, P. et al. (Orgs.).Papel da memória. Tradução e introdução José Horta Nunes. Campinas: Pontes Editores, 1999. p. 49-57.

PFEIFFER, C. R. C. Escola e Reforma do Ensino Médio no Brasil - lugar de leitura do professor de língua portuguesa. PRELO. Anais do X Congresso da ABRALIN, Niterói, UFF, 2017.

. Políticas públicas de ensino. In: ORLANDI, E. P. (Org.).Discurso e políticas públicas urbanas: a fabricação do consenso. Campinas: Editora RG, 2010. p. 85-99.

. Que autor é este? Dissertação de mestrado. IEL/UNICAMP. Campinas, 1995.

SILVA, M. V. da. Uma Base Nacional Curricular Comum para a leitura nas escolas brasileiras: a política e o político. In:FLORES, G. et al. (Orgs.).Análise de discurso em rede: cultura e mídia - volume 3. Campinas: Pontes Editores, 2017.p. 315-332.

Documentos analisados:

BRASIL. Base nacional comum curricular, 2ª versão revista, 2016.

BRASIL. Base nacional comum curricular, 2017.

BRASIL. Lei 13.415/2017 (Lei que reforma o ensino médio).

BRASIL, EM. 84/2016/MEC (Documento do MEC que encaminha o projeto de lei da reforma do ensino médio à Presidência da República).

MINISTÉRIO DA EDUCAÇÃO - informações sobre a reforma do ensino médio: http://portal.mec.gov.br/component/content/article?id=40361 
PORTAL G1 - Entenda a reforma do ensino médio em https://g1.globo.com/educacao/noticia/entenda-a-reforma-do-ensino-medio.ghtml PORTAL NOVA ESCOLA -N Notícias (Nova Escola): 13 respostas sobre o Novo Ensino Médio em https://novaescola.org.br/conteudo/4742/13-respostas-sobre-o-novo-ensino$\underline{\text { medio }}$

SENADO FEDERAL. LDB - Lei de diretrizes e bases da educação nacional, Edição atualizada até março de 2017.

Recebido em 27/07/2018. Aprovado em 03/10/2018. 